\title{
Association between dating violence and personality type in Mexican university students
}

\author{
Karla L. Cortés-Treviño ${ }^{1,2} \cdot$ Adriana Garduño-Alanis $^{2,3}$ (ID $\cdot$ Guadalupe Villalobos Monroy ${ }^{4}$
}

Accepted: 29 October 2020 / Published online: 5 November 2020

(C) The Author(s) 2020

\begin{abstract}
Violence against women is a global health problem. Some pathological personality traits have been associated with violence. However, the relation between personality type and dating violence, especially in Mexican students, is not fully known. Therefore, the aim of this study is to evaluate the relation between personality type and dating violence in female university students of the State of Mexico, Mexico. Cross-sectional study conducted from February to September 2019 at a private university in the State of Mexico, Mexico. Female students of the bachelor's degrees in the field of health sciences were included. Socio-demographic data, dating violence, and personality type were evaluated through questionnaires. Adjusted logistic regression models were applied, using STATA v.13. Students with an extroverted personality were 2.45 more likely to suffer dating violence (95\% CI 1.29 to 4.63), adjusted for covariates. Those who reported childhood abuse (OR =2.33, 95\% CI 1.08 to 5.01) and whom their partners had a history of drug use $(\mathrm{OR}=2.78,95 \% \mathrm{CI} 1.17$ to 6.60$)$ or who currently use drugs $(\mathrm{OR}=4.85,95 \%$ CI 0.92 to 25.7), were more likely to suffer dating violence, adjusted for covariates. Students with extroverted personality were more likely to experience dating violence, compared to those with introverted personality. The results show the need to produce further research to identify specific traits within extroverted female population which makes them vulnerable to dating violence.
\end{abstract}

Keywords Personality types $\cdot$ Dating violence $\cdot$ Mexico $\cdot$ Cross-sectional study

\section{Introduction}

Violence against women, especially dating and sexual violence, constitute a serious public health problem and a violation of women's human rights (WHO, 2017). Thirty five percent of women worldwide have suffered some type of physical and / or sexual dating violence or sexual violence by third parties at some time in their lives (WHO, 2017). This violence can negatively affect their physical, mental, sexual and

Adriana Garduño-Alanis adrisgamx@hotmail.com

1 Centro de Investigación Multidisciplinaria en Educación, Universidad Autónoma del Estado de México, Toluca, Mexico

2 Research Department, Universidad de la Salud del Estado de México, Vialidad Toluca Atlacomulco 1946 Col. La Aviación, C.P, 50295 Toluca, Mexico

3 Instituto de Investigación y Desarrollo de Tecnologías Garman, Santiago de Querétaro, A.C. Querétaro, Mexico

4 Facultad de Ciencias de la Conducta, Universidad Autónoma del Estado de México, Toluca, Mexico reproductive health, and even increase the risk of acquiring sexually transmitted diseases (WHO, 2017). Mexico is one of the 25 countries with the highest prevalence of violence against women (Geneva Declaration Secretariat, 2015). According to the latest national survey on violence against women, between 2003 and 2006 the prevalence of dating violence increased by $17 \%$; this means that in 2006 one in three women suffered this type of violence, compared to one in five in 2003 (Ávila-Burgos et al., 2014). Recent studies show that, between 1990 and 2015, violence against women in Mexico remained within the main causes of death for the age group of 20 to 24 years, where the State of Mexico is one of the five states of the country with the highest rate of violence against this vulnerable group (Romero Mendoza et al., 2018).

Violence against women includes dating violence, which can be defined as a repetitive pattern of male partner abuse against women, and involves the following types of violence: a) physical: pushes, blows, gunshot or puncture wounds, b) emotional: intimidation, humiliation, threats, c) sexual: physically or emotionally forcing sexual intercourse, and d) economic: controlling by means of money (Olaiz, Uribe, \& DelRio, 2009). This kind of violence has been measured with 
scales such as the Index of Severity Partner Violence (ISPV), which has been validated in the Mexican population, and allows to classify the partner violence into: a) no violence, $b$ ) non-severe violence, and c) severe violence (Avila-Burgos et al., 2009; Ávila-Burgos et al., 2014; Valdez-Santiago et al., 2006). Women experiencing violence is related to factors such as: child abuse, rape, partner alcoholism, low degree of education (Ávila-Burgos et al., 2014; Blom, Högberg, Olofsson, \& Danielsson, 2014), work activity (Canedo \& Morse, 2019), age, smoking, drug use, and place of living (Blom et al., 2014); while both, perpetrators and those experiencing violence, share factors such as socioeconomic status, gender (Ulibarri et al., 2019) and personality type (Boladale, Yetunde, Adesanmi, Olutayo, \& Olanrewaju, 2015; Dowgwillo, Ménard, Krueger, \& Pincus, 2016). Regarding personality type, it is known that the presence of certain disorders and personality traits in the aggressors is related to dating violence (Boladale et al., 2015; Dowgwillo et al., 2016). However, the relation between dating violence and the woman's personality type is a complex phenomenon that has not been fully explored, especially in Mexican university students (Ávila-Burgos et al., 2014; Boladale et al., 2015; Rivera-Rivera, Allen-Leigh, Rodríguez-Ortega, Chávez-Ayala, \& Lazcano-Ponce, 2007).

Personality is made up, among other things, of the external and visible characteristics that people perceive from someone else. This term also includes several subjective features, both social and emotional, that cannot be observed directly and that a person might try to hide (Schultz \& Shultz, 2009). Personality is developed from childhood to adulthood, and is determined based on what a person is and wishes to become (Schultz \& Shultz, 2009). This has been measured through different perspectives and instruments. (Boladale et al., 2015; Dowgwillo et al., 2016; Hines \& Saudino, 2008; Jafrani et al., 2017; Martinou, Allan, \& Vig, 2015; Ulloa, Hammett, O’Neal, Lydston, \& Aramburo, 2016).

In 1913, psychologist Carl Jung classified personality in different types to identify individuals. Based on Jung's work, in the 1920s Katharine Briggs and Isabel Briggs-Myers developed the Myers-Briggs Type Indicator (MBTI) which assessed 16 different personality types. These personality types are based on four dimensions with dichotomous responses in each of them; I. Preference to socialize, II. Preference to gather information, III. Preference for decision making, and IV. Preference to organize life. These four dimensions help people think, judge, perceive, feel, and deal with their environment (Jafrani et al., 2017; Schultz \& Shultz, 2009; Shirzad, 2016; The Myers and Briggs Foundation, 2020; Yang, Richard, \& Durkin, 2016). Although the MBTI has been used in diverse studies and is known worldwide (Jafrani et al., 2017; Schultz \& Shultz,
2009), it has not been yet explored for various health issues such as dating violence.

Different scales have been used to measure the relation between personality traits and dating violence. However, these have mainly focused on psychopathologies already explored, for example: the Eysenck Personality Questionnaire, the Personality Inventory for the DSM-5, the Schedule for Nonadaptive and Adaptive Personality-II, or the Personality Assessment Screener (Boladale et al., 2015; Carleton, Mulvogue, \& Duranceau, 2015; Dowgwillo et al., 2016; Porcerelli, Hurrell, Cogan, Jeffries, \& Markova, 2015) putting personality types considered normal aside. When using the MBTI, it is possible to measure the personality type without considering it as pathological (Schultz \& Shultz, 2009), thus aiding to identify the relation between the personality type and dating violence. Together, these types of assessments could inform prevention programs for dating violence, regardless of violence taking place and prevent the future likelihood of violence in intimate relationships (Boladale et al., 2015; Carleton et al., 2015; Dowgwillo et al., 2016; Falb et al., 2014; Porcerelli et al., 2015).

Interpersonal relationships during adolescence include parent-child and teacher-student relationships, however during this period, adolescents spend more time with their peers and such relationships become more important and influential for this age group (Papalia, Feldman, \& Martorell, 2015). At this stage, despite being considered a period of low mortality and good health, it is also a period of physical, social, and emotional changes which exposed women to: sexual activity, substance abuse, unemployment, undesired pregnancies, sexual abuse, depression, violence, young marriage, abortions, traffic accidents, and difficulties of educational achievements (Romero Mendoza et al., 2018). In addition, the beginning of university life and the transition from high school to the university includes greater challenges to the life of a young adult (Shirzad, 2016). Therefore, due to the importance of dating violence in this age group, this study hypothesis is: personality type is an associated factor to suffer dating violence in Mexican university students. The aim of this study is to evaluate the relationship between personality type using the MBTI scale and dating violence measured through the ISPV scale in female university students.

\section{Methods}

\section{Study Design}

Cross-sectional study conducted from February to September 2019 at the Universidad de la Salud del Estado de Mexico (UNSA), Mexico. 


\section{Participants}

Female students of the bachelor's degree programs in Medicine, Nursing, Gerontology, Physical Therapy and Psychology were invited to participate in the study. According to the Organization of Economic Cooperation and Development, middle class is defined as income between $75 \%$ to $200 \%$ of the average national income, in this case a three person household ranging from $\mathrm{MX} \$ 6548$ to MX $\$ 17,460$ per month; after living expenses, the average monthly tuition falls in between this range, thus all students were considered belonging at least to a medium socioeconomic status (Organization of Economic Cooperation and Development, 2019). Considering a universe of 625 women, a sample size calculation of 238 students was obtained (alpha $=0.05, \mathrm{Z}$ alpha $=1.96$, and $95 \%$ confidence level). A total of 525 students were invited to participate in the study, where 524 of them agreed to be part of it. From these, 332 met the inclusion criteria, reporting having a partner at the time of the study or during the previous year. Those who had incomplete data on the MBTI and / or the ISPV questionnaires $(n=59)$ and in the covariates $(n=32)$ were excluded from the study. After these exclusions, the final sample for the statistical analysis was 241 women.

\section{Data Collection}

The study was conducted in two phases at UNSA facilities. Initially, a qualified psychologist employed the MBTI questionnaire to explore students' personality types (exposure variable). Subsequently, students provided their answers electronically in order to obtain information on dating violence (outcome variable) and covariates.

\section{Dating Violence}

In order to obtain this variable, some questions from the National Survey of Violence against Women (Olaiz et al., 2009), as well as the ISPV (Valdez-Santiago et al., 2006) were used. This index has been previously used in the Mexican population (Avila-Burgos et al., 2009; Ávila-Burgos et al., 2014; Valdez-Santiago et al., 2006), enabling the categorization of violence according to the following cutting points: a) no violence: women who obtained values up to the average in the ISPV; b) non-severe violence: women who obtained values above the average in the ISPV plus one standard deviation; and c) severe violence: women with values above the average plus one standard deviation (Ávila-Burgos et al., 2014). The frequency of violent acts during the previous year was recorded on a 4-point scale for each item $(0=$ never, $1=$ once, $2=$ occasionally, and $3=$ many times) (Avila-Burgos et al., 2009). Interviewed women were the ones who provided information about their partners.

\section{Personality Types}

The MBTI questionnaire (The Myers and Briggs Foundation, 2020) was used to determine the personality type. These works provided dichotomous responses to sentences that described the four dimensions of personality, and are, at the same time, classified into four categories with two options each. The participants classified their personality into four dimensions of the MBTI represented by a single capital letter. These dimensions with dichotomous response options are summarized as follows: Dimension I. Preference to socialize: it classifies people as Extroverted $(E)$ or Introverted (I). Extroverts focus on the outside world of people and things, while Introverts focus on the inner world of ideas and expressions; Dimension II. Preference for gathering information: classifies the person as Sensor $(S)$ or Intuitive $(N)$. Sensors focus on the present and the concrete information obtained from senses, while Intuitive people in the future with an emphasis on patterns and possibilities; Dimension III. Preference for decision-making: classifies the person as Thinker $(T)$ or Feeler $(F)$. Thinkers base their decisions on logic and objective analysis, while Feelers base decisions primarily on values and subjective assessments of person-centered concerns; Dimension IV. Preference for organizing life: classifies the person as Judging $(J)$ or Perceptive $(P)$. Judging people are structured and prefer a planned and organized approach to life, while Perceptive people enjoy a flexible and spontaneous approach to life. Based on this information, the personality type was determined in the last part of the questionnaire. Consequently, each personality was made up of these four dimensions, so that 16 personality types were obtained (Jafrani et al., 2017; The Myers and Briggs Foundation, 2020). Despite the MBTI has already been used in students of the health area (Jafrani et al., 2017; Martinou et al., 2015), an internal validity of the instrument was also obtained with an $\alpha$-cronbach $=0.76$. (González \& Pazmiño, 2015; Mcneish, 2018).

\section{Covariates}

The covariates considered as potentially confounders in multivariate models were: age, smoking, alcohol consumption, childhood abuse, drug use (other than tobacco and alcohol) (Blom et al., 2014; Rothman et al., 2011), and partner variables: education, work activity, alcohol consumption, and drug use (other than tobacco and alcohol) (Avila-Burgos et al., 2009; Ávila-Burgos et al., 2014).

\section{Statistical Analysis}

The analysis was performed with STATA version 13 (StataCorp, College Station, TX, US). The $p$ value $<0.05$ was considered statistically significant. Data normality was identified 
by histograms, normal curves and descriptive measures. For their description, mean and standard deviation $(S D)$ were used in continuous variables, and proportions and percentages in categorical variables. The 16 personality types obtained from the MBTI were shown descriptively, and the four dichotomous dimensions of the MBTI were considered as exposure variables in the regression models. Due to the low prevalence of severe violence, the responses of the ISPV were transformed into a dichotomous variable, reclassifying in two categories, "no dating violence", score $=0$, and "dating violence", score from 1 to 81 . In order to know the association between the variables, $t$-test, chi trend, and chi2 were used in the bivariate analysis, furthermore logistic regression models were used for the multivariate analysis. All associations were evaluated in three models. Model 1 was adjusted for age, model 2 was additionally adjusted for smoking, alcohol consumption, drug use (other than tobacco and / or alcohol), and childhood abuse. Finally, in model 3 variables related to the partner (education, work activity, alcohol consumption, and drug use other than tobacco and / or alcohol) were added in the adjustment. Interactions were tested in the models finding out no significant covariates in this analysis.

\section{Ethics}

Prior to their inclusion in the study, all participants signed an informed consent. The study protocol was approved by UNSA Ethics Committee, based on ethical standards of the Helsinki Declaration of 1964 and its subsequent updates.

\section{Results}

The 16 personality types obtained based on the MBTI are described in Table 1, the ISFJ (Introverted, Sensor, Feeler,

Table 1 Frequency of the 16 personality types in university women in the State of Mexico, Mexico $(n=241)$
Personality Type according to MBTI, $\mathrm{n}$ (\%)

\begin{tabular}{lclr}
\hline ISTJ & $21(8.7)$ & INTJ & $5(2.1)$ \\
ISFJ & $40(16.6)$ & INFP & $18(7.5)$ \\
ISTP & $34(14.1)$ & INTP & $10(4.2)$ \\
ISFP & $39(16.2)$ & ESTP & $12(4.0)$ \\
INFJ & $5(2.1)$ & ESFP & $16(6.6)$ \\
ESTJ & $10(4.2)$ & ENTP & $5(2.1)$ \\
ESFJ & $9(3.7)$ & ENFJ & $3(1.2)$ \\
ENFP & $12(4.0)$ & ENTJ & $2(0.8)$ \\
\hline
\end{tabular}

$M B T I$, Myers-Briggs Type Indicator, $E$ extroverted, $I$ introverted, $S$ sensor, $N$ intuitive, $T$ thinker, $F$ feeler, $J$ judging, $P$ perceptive and Judging) had the highest frequency. According to the ISPV scale, during the last year, $98.8 \%$ suffered no violence, $0.4 \%$ non-severe violence, and $0.8 \%$ severe violence. However, the responses of this scale were reclassified for the statistical analysis, where the prevalence of dating violence was $63 \%$ (score $\geq 1$ on the ISPV scale).

In Table 2, dating violence was associated with the variables smoking, child abuse, and drug use other than tobacco and / or alcohol by the partner. Dating violence was more common in smoking students, those who suffered child abuse, and those whose partners use drugs other than tobacco and / or alcohol. In the bivariate analysis shown in Table 3, the preference to gather information was associated with the variables of smoking and drug use other than tobacco and / or alcohol, so that the Sensor students' (75\% of the total) main characteristics were not being smokers or having used other drugs, compared to Intuitive students. The preference to organize life was associated with the variable of alcohol consumption, so Perceptive students' (61\%) main characteristic was a high rate of alcohol consumption, compared to Structured students. Introverted students accounted for $71.4 \%$ of the total in terms of preference to socialize, and Feeler students accounted for $59 \%$ of the total in terms of preference for decision-making.

Table 4 shows the results of the logistic regression models adjusted for the association of dating violence and the four personality dimensions. Extroverted personality was strongly associated with suffering from dating violence $(\mathrm{OR}=2.45$, 95\% CI 1.29 to $4.63, p=0.006$ ), adjusted for age, smoking, alcohol consumption, drug use, child abuse, and the partner variables (education, work activity, alcohol consumption, and drug use). In model 3 , the associations with the variables of child abuse and drug use by the partner remained statistically significant. Compared to those who did not report child abuse, those who did suffer from it were 2.33 times more likely to suffer dating violence (95\% CI 1.08 to $5.01, p=0.030$ ), adjusted by preference to socialize, age, smoking, alcohol consumption, drug use other than tobacco and / or alcohol, and the partner variables (education, work activity, alcohol consumption, and drug use other than tobacco and / or alcohol). The students whose partners had a history of using drugs other than tobacco and / or alcohol $(\mathrm{OR}=2.78,95 \% \mathrm{CI} 1.17$ to $6.60)$ or who currently use them $(\mathrm{OR}=4.85,95 \%$ CI 0.92 to 25.7), were more likely to suffer from dating violence, compared to those who did not report using them, adjusted by preference to socialize, age, smoking, alcohol consumption, drug use other than tobacco and / or alcohol, child abuse, and the partner variables (education, work activity, and alcohol consumption). Testparm was used to verify the general statistical significance of the variable "drug use other than tobacco and / or alcohol" in the partner. Emotional and Perceptive personality were related to dating violence, and Sensor personality was related to a lower risk of dating violence. However, these associations were not statistically significant. 


\section{Discussion}

In this study, we investigated the presence of dating violence and its relationship with personality. According to the ISPV, a low prevalence of severe dating violence was found. However, most students reported having suffered at least one episode of dating violence. Therefore, the analysis carried out with the ISPV reclassification indicated that students with

Table 2 Relationship between dating violence and covariates

\begin{tabular}{|c|c|c|c|c|}
\hline \multirow[t]{2}{*}{ Variables } & \multirow[b]{2}{*}{$\begin{array}{l}\text { Total } \\
n=241\end{array}$} & \multicolumn{2}{|l|}{ Dating Violence } & \multirow[b]{2}{*}{$p$ Value } \\
\hline & & $\begin{array}{l}\text { No } \\
n=89(36.9 \%)\end{array}$ & $\begin{array}{l}\text { Yes } \\
n=152(63.1 \%)\end{array}$ & \\
\hline Age, mean (SD) & & $19.6(1.2)$ & $19.5(3)$ & $0.962 *$ \\
\hline Smoking, n (\%) & & & & $0.042 * *$ \\
\hline No & 88 & $40(45.4)$ & $48(54.6)$ & \\
\hline Yes, but no longer & 102 & $34(33.3)$ & $68(66.7)$ & \\
\hline Yes & 51 & $15(29.4)$ & $36(70.6)$ & \\
\hline Alcohol consumption, $\mathrm{n}(\%)$ & & & & $0.256 * *$ \\
\hline No & 23 & $13(56.5)$ & $10(43.5)$ & \\
\hline Low (< once a month) & 110 & $38(34.6)$ & $72(65.4)$ & \\
\hline Moderate (once a month) & 49 & $18(36.7)$ & $31(63.3)$ & \\
\hline High (> once a month) & 59 & $20(33.9)$ & $39(66.1)$ & \\
\hline Drug use other than tobacco and / or alcohol, n (\%) & & & & $0.243 * *$ \\
\hline No & 204 & $79(38.7)$ & $125(61.3)$ & \\
\hline Yes, but no longer & 31 & $8(25.8)$ & $23(74.2)$ & \\
\hline Yes & 6 & $2(33.3)$ & $4(66.7)$ & \\
\hline Childhood abuse, n (\%) & & & & $0.005 * * *$ \\
\hline No & 181 & $76(42)$ & $105(58)$ & \\
\hline Yes & 60 & $13(21.7)$ & $47(78.3)$ & \\
\hline \multicolumn{5}{|l|}{ Partner Variables } \\
\hline Education, $\mathrm{n}(\%)$ & & & & $0.793 * *$ \\
\hline Low (Elementary or Unknown) & 17 & $6(35.3)$ & $11(64.7)$ & \\
\hline Medium (High School) & 102 & $37(36.3)$ & $65(63.7)$ & \\
\hline High (College or postgraduate) & 122 & $46(37.7)$ & $76(62.3)$ & \\
\hline Work Activity, n (\%). The person... & & & & $0.847 * *$ \\
\hline Does not study or work & 6 & $2(33.3)$ & $4(66.7)$ & \\
\hline Works & 129 & $49(38)$ & $80(62)$ & \\
\hline Studies & 51 & $18(35.3)$ & $33(64.7)$ & \\
\hline Studies and works & 55 & $20(36.4)$ & $35(63.6)$ & \\
\hline Alcohol consumption, n (\%) & & & & $0.922 * *$ \\
\hline No & 62 & $19(30.7)$ & $43(69.3)$ & \\
\hline Low (< once a month) & 66 & $30(45.4)$ & $36(54.6)$ & \\
\hline Moderate (once a month) & 489 & $19(39.6)$ & $29(60.4)$ & \\
\hline High (> once a month) & 65 & $21(32.3)$ & $44(67.7)$ & \\
\hline Drug use other than tobacco and / or alcohol, n (\%) & & & & $0.001 * *$ \\
\hline No & 172 & $75(43.6)$ & $97(56.4)$ & \\
\hline Yes, but no longer & 57 & $12(21)$ & $45(79)$ & \\
\hline Yes & 12 & $2(16.7)$ & $10(83.3)$ & \\
\hline
\end{tabular}

ISPV Index of Severity of Partner Violence, $S D$ standard deviation

No dating violence (ISPV score $=0$ ) vs Yes dating violence (ISPV score $\geq 1$ )

$* t$-test; $* *$ chi trend; $* * *$ chi ${ }^{2}$

$p<0.05$ was considered statistically significant 


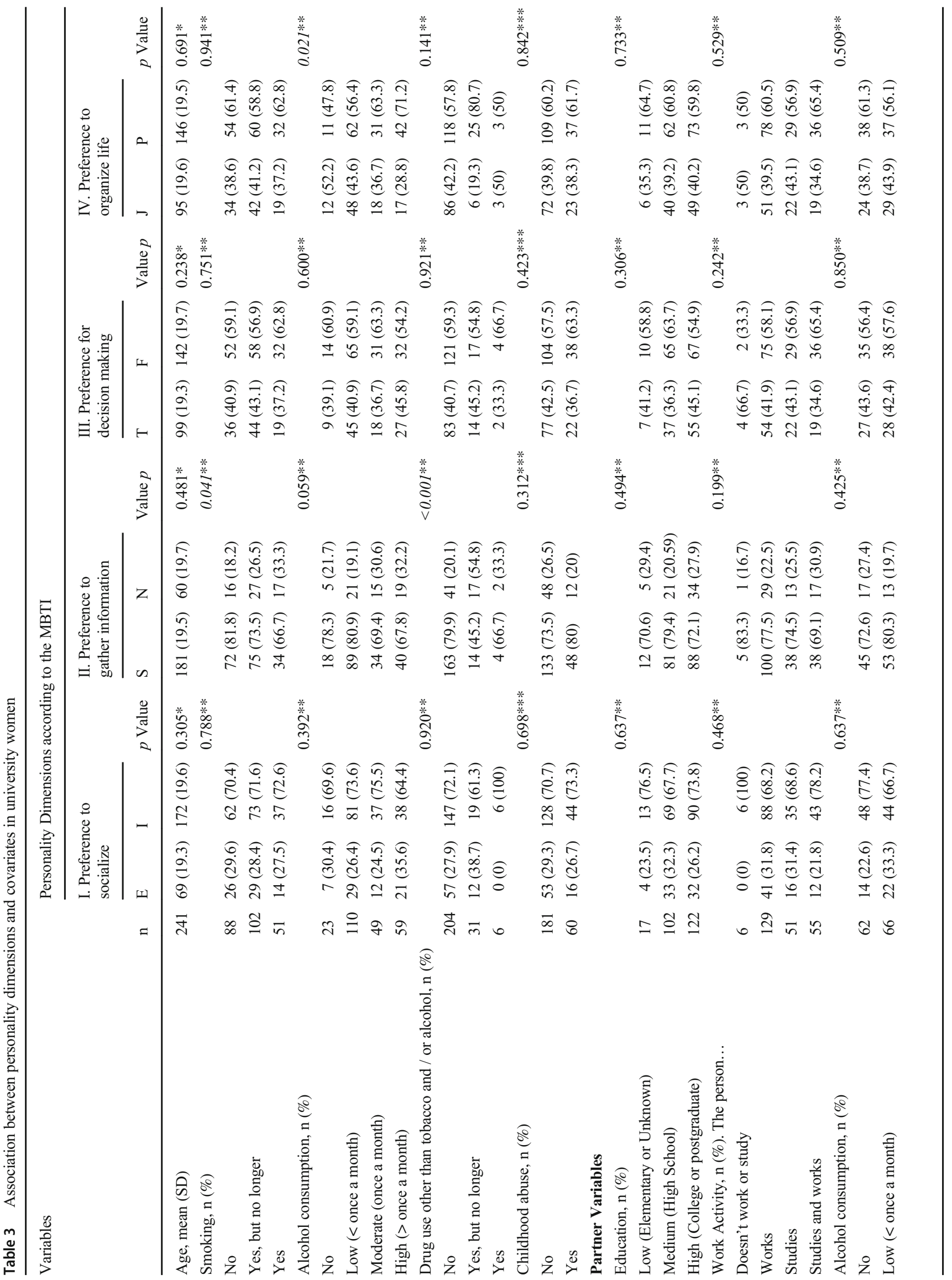


Extroverted personality were more likely to suffer dating violence compared with those with Introverted personality. Child abuse and drug use by the partner were also related to dating violence.

From the total, $63 \%$ reported having suffered one or more of the episodes of violence indicated by the ISPV. Although the presence of dating violence might be modified depending on the instrument which it is measured with, the results found out are below the national (Ávila-Burgos et al., 2014) and international prevalence (Boladale et al., 2015; WHO, 2017), considering that less than $2 \%$ reported suffering from severe dating violence. In contrast to what was reported by Romero et al., there was not a high rate of severe violence in this study, probably due to the characteristics of the population studied, since populations owning a higher education and sociocultural level have a protection factor against this type of violence (Gupta et al., 2018; Romero Mendoza et al., 2018). Moreover, although the female gender is considered as a vulnerability factor to suffer violence, the population studied does not come from marginal or conflict areas, fact assumed due to their university affiliation and income level, which could potentially expose this gender to dating violence (Espinoza, Hokoda, Ulloa, Ulibarri, \& Castaneda, 2012; Rivera-Rivera et al., 2007; Romero Mendoza et al., 2018).

The bivariate analysis findings regarding the relationship among smoking, childhood abuse, and drug use by the partner in the dating violence are consistent with the literature (Abajobir, Kisely, Williams, Clavarino, \& Najman, 2017; Avila-Burgos et al., 2009; Blom et al., 2014; Rivera-Rivera et al., 2007; Temple, Shorey, Fite, Stuart, \& Le, 2013). For example, in a cohort study conducted in young women, it was observed that the risk of reporting severe partner violence was 3.97 and 4.62 times higher in those who suffered from emotional abuse and neglect during childhood, respectively. (Abajobir et al., 2017) Similar results were observed in the Mexican population, where those who had a history of childhood abuse were 3.7 more likely to suffer from severe partner violence (Avila-Burgos et al., 2009). Similarly, in a longitudinal study with American students, it was observed, through models of structural equations, that the use of drugs at the beginning of the study predicted the presence of partner violence, even with the adjustment for family violence and other factors. Regarding the relationship between tobacco use and dating violence, this association was not persistent in the multivariate analysis. This agrees with other studies where the initial association of these two elements may have been due to the correlation between smoking and other drugs (McNaughton Reyes, Foshee, Bauer, \& Ennett, 2014).

Regarding the results on personality dimensions, those who had preference to gather information of Sensory (S) type were characterized by having a healthier lifestyle (Petrides, Collins, Kowalski, Sepede, \& Vermeulen, 2019). Although the evidence on healthy behaviors in these personalities is 
limited, it is known that those who are Sensors (S) tend to process information through their senses, and to be concrete thinkers who recognize details, opposite to Intuitives $(\mathrm{N})$, who are people focused on how the present would affect the future, more analytical and able to catch abstract concepts (The Myers Briggs Foundation, 2020). According to Devynk et al., in a cross-sectional study, those who had a more abstract-analytical thinking, like the Intuitives $(\mathrm{N})$, tent to develop depression and anxiety, symptoms which also were associated with an unhealthy lifestyle like a higher alcohol consumption (Devynck, Kornacka, Sgard, \& Douilliez, 2016). Their results were compared with those patients which had a concrete-experimental thinking, like Sensors (S), who were characterized by an attention focused on the direct experience of the current situation (Devynck et al., 2016). Additionally, findings from another prospective study carried on adolescents victims of dating violence, showed that those who had problems to cope with negative thought processes, were also in a higher risk drug use and to alcohol consumption (Miller, Williams, Day, \& Esposito-Smythers, 2017). These could explain how those Sensors (S) had a healthier lifestyle. On the other hand, students whose preference to organize life belonged to the Perceptive (P) type reported a high alcohol consumption. This could be explained due to these personalities are characterized by preferring flexibility and living their lives spontaneously, as well as being open mind to new options and experiences (The Myers Briggs Foundation, 2020). However, both associations did not remain in multivariate analyzes regarding personality and violence.

Finally, the findings of the multivariate analysis regarding the relationship between personality and dating violence are consistent with the literature (Boladale et al., 2015; Coskuner Potur, Onat, \& Doğan Merih, 2019; Dowgwillo et al., 2016; Hines \& Saudino, 2008 ; Ulloa et al., 2016). Although in a cross-sectional study conducted with university students showed a relationship between psychosis and neurosis with dating violence, the association with extroversion and violence was not statistically significant (Boladale et al., 2015). Despite the findings related to extroversion are not widely explained in that study, the difference with our results may be due to the type of instruments used to measure personality. Additionally, in despite of the fact that several studies evaluate psychopathological aspects of personality and its relationship with dating violence (Boladale et al., 2015; Dowgwillo et al., 2016), few have focused on assessing non-pathological personality traits (Hines \& Saudino, 2008; Shirzad, 2016; Ulloa et al., 2016). In a cross-sectional study with American university students, it was found that the most extroverted women were the ones who mostly attacked their partners psychologically and sexually (Hines \& Saudino, 2008). However, they were also the ones who were the most attacked psychologically (Hines \& Saudino, 2008). Furthermore, in another crosssectional study in the American population, it was found that extroversion was one of the most important risk factors associated with dating violence in female students, such personality trait being associated with both victimization and perpetuation of violence. (Ulloa et al., 2016). Both studies agreed with our results, where female students owning an extroverted personality were more likely to suffer dating violence. Although this could be partially explained according to the tendency that extrovert personalities have of being open mind to new experiences and seeking more aggressive emotions and,

Table 4 Multivariate logistic regression model for dating violence and personality dimensions

\begin{tabular}{|c|c|c|c|c|c|c|c|c|c|c|c|}
\hline \multirow[t]{2}{*}{ Exposure Variable } & & \multirow[b]{2}{*}{$\mathrm{n}$} & \multicolumn{3}{|c|}{ Model 1} & \multicolumn{3}{|c|}{ Model 2} & \multicolumn{3}{|c|}{ Model 3} \\
\hline & & & OR & CI $95 \%$ & Value $p$ & OR & CI $95 \%$ & Value $p$ & OR & $95 \% \mathrm{CI}$ & Value $p$ \\
\hline \multicolumn{12}{|c|}{ Personality Dimensions according to MBTI } \\
\hline \multirow[t]{2}{*}{ I. Preference to socialize } & Introverted (I) & 172 & ref. & & & & & & & & \\
\hline & Extroverted (E) & 69 & 2.45 & $1.29,4.63$ & 0.006 & 02.67 & $1.37,5.18$ & 0.004 & 3.00 & $1.46,6.07$ & 0.002 \\
\hline \multirow[t]{2}{*}{ II. Preference to gather information } & Intuitive $(\mathrm{N})$ & 60 & ref. & & & & & & & & \\
\hline & Sensor $(\mathrm{S})$ & 181 & 0.76 & $0.42,1.39$ & 0.382 & 0.69 & $0.36,1.33$ & 0.278 & 0.67 & $0.34,1.33$ & 0.257 \\
\hline \multirow[t]{2}{*}{ III. Preference for decision making } & Thinker $(\mathrm{T})$ & 99 & ref. & & & & & & & & \\
\hline & Feeler $(\mathrm{F})$ & 142 & 1.12 & $0.65,1.91$ & 0.674 & 1.15 & $0.66,2.01$ & 0.605 & 1.18 & $0.66,2.11$ & 0.569 \\
\hline \multirow[t]{2}{*}{ IV. Preference to organize life } & Judging (J) & 95 & ref. & & & & & & & & \\
\hline & Perceptive $(\mathrm{P})$ & 146 & 1.58 & $0.91,2.74$ & 0.097 & 1.78 & $0.99,3.18$ & 0.051 & 1.75 & $0.96,3.18$ & 0.067 \\
\hline
\end{tabular}

MBTI Myers-Briggs Type Indicator, ISPV Index of Severity of Partner Violence, $C I$ confidence interval, ref. reference; $(\mathrm{n}=241)$

No dating violence (ISPV score $=0$ ) vs. Yes dating violence (ISPV score $\geq 1$ )

Model 1: adjusted for age, Model $2=$ model $1+$ smoking + alcohol consumption + drug use other than tobacco and $/$ or alcohol + childhood abuse, Model 3 = model $2+$ partner variables (education + work activity + alcohol consumption + drug use other than tobacco and / or alcohol

$p<0.05$ was considered statistically significant 
consequently, being more likely to participate in dangerous and aggressive behaviors (Hines \& Saudino, 2008; Ulloa et al., 2016). This could also be due to the propensity that these women have in order to participate in arguments and be more anxious than women who are less extroverted to address their problems. Therefore, such actions could increase the likelihood of women behaving violently with their partners or vice versa (Ulloa et al., 2016).

Within the limitations of the study, the research design implies that temporality is uncertain and it is not possible to determine causal inference (Esquivel-Santoveña, RodríguezHernández, Gutiérrez-Vega, Castillo-Viveros, \& LópezOrozco, 2019; Levin, 2006). In addition, the representativeness of the sample might have been affected by its method of selection. However, $84 \%$ of the population were invited to participate, and a high response rate of $99.8 \%(n=525)$ was obtained (Levin, 2006; Sedgwick, 2015). Only 16\% $(n=100)$ of the population was not invited to participate in the study since, during the application of the surveys, some academic activities took place outside the campus causing the absence of students. There may have been information bias through a underreport of exposure to violence, smoking, alcohol consumption, or other drugs, as well as in those responses related to personality type, whether due to shame, fear or lack of sincerity in the responses (Hernández-Avila, Garrido, \& Salazar-Martínez, 2000; Sedgwick, 2015). Nevertheless, both the MBTI and the ISPV have coded questions where the participants can remain blinded to the study hypothesis. In order to reduce the recall bias, the information collected about the past was objective and / or related to the last year of exposure. Regarding the observer bias, this was minimal, considering that the staff did not know the objective of the study during the application of the surveys (Hernández-Avila et al., 2000; Sedgwick, 2015). Concerning the covariates, despite dating violence in this research was considered as a repetitive pattern of male to female abuse and not vice versa, it's important to measure perpetration given that other studies consider both as dating violence (Olaiz et al., 2009; Ulloa et al., 2016). Nevertheless, in the reviewed literature, we were unable to find validated questionnaires for measuring both factors in Mexican population (Avila-Burgos et al., 2009; ÁvilaBurgos et al., 2014; Valdez-Santiago et al., 2006). Future research could develop further assessments to measure both aspects in dating violence in this population. Lastly, although the lack of external validity did not allow to extrapolate the results to other populations, the reliability of the scales was guaranteed by a good internal consistency (>0.7) (González \& Pazmiño, 2015; Mcneish, 2018).

The strength of this study is that it allows to know the relationship between personality and dating violence from non-pathological features of the person, which makes the approach with students easier at the time of an evaluation through the use of instruments like the MBTI. In addition, a high response rate was obtained, which allowed the results to be generalized to the population studied (Levin, 2006). This could be due to the profile of our population, because it has been observed that those who do participate in studies are likely to own higher education and socioeconomic status than those who do not participate (Sedgwick, 2015).

The results of this study suggest the need of considering extroversion and introversion personality traits in programs focused in the reduction and / or prevention of dating violence in female students (Boladale et al., 2015; Falb et al., 2014). Additionally, knowing the students' personality type might help their tutors in the orientation of the stress management and the professional and personal development in these students (Martinou et al., 2015). This study is one of the few that examine the relationship between personality and dating violence in Mexican students. Those students with an extroverted personality were more likely to suffer partner violence. The results show the need to produce further research to identify specific traits within extroverted female population which makes them vulnerable to dating violence.

Acknowledgments The authors gratefully acknowledge Universidad de la Salud del Estado de Mexico Staff for their contributions to this study.

Availability of Data and Material The datasets generated during and/or analyzed during the current study are available from the corresponding author on reasonable request.

Authors' Contributions All authors contributed to the study conception and design. Material preparation, data collection and analysis were performed by Karla L. Cortés-Treviño and Adriana Garduño-Alanis. The first draft of the manuscript was written by Karla L. Cortés-Treviño and all authors commented on previous versions of the manuscript. All authors read and approved the final manuscript.

Funding This study was funded by the authors.

\section{Compliance with Ethical Standards}

Conflict of Interest The authors declare that they have no conflict of interest.

Ethics Approval All procedures performed in studies involving human participants were in accordance with the ethical standards of the institutional and/or national research committee and with the 1964 Helsinki Declaration and its later amendments or comparable ethical standards. The study was approved by the Ethics Committee of the Universidad de la Salud del Estado de Mexico.

Consent to Participate Informed consent was obtained from all individual participants included in the study.

Consent for Publication Participants signed informed consent regarding publishing their data.

Code Availability Not applicable. 
Open Access This article is licensed under a Creative Commons Attribution 4.0 International License, which permits use, sharing, adaptation, distribution and reproduction in any medium or format, as long as you give appropriate credit to the original author(s) and the source, provide a link to the Creative Commons licence, and indicate if changes were made. The images or other third party material in this article are included in the article's Creative Commons licence, unless indicated otherwise in a credit line to the material. If material is not included in the article's Creative Commons licence and your intended use is not permitted by statutory regulation or exceeds the permitted use, you will need to obtain permission directly from the copyright holder. To view a copy of this licence, visit http://creativecommons.org/licenses/by/4.0/.

\section{References}

Abajobir, A. A., Kisely, S., Williams, G. M., Clavarino, A. M., \& Najman, J. M. (2017). Substantiated childhood maltreatment and intimate partner violence victimization in young adulthood: A birth cohort study. Journal of Youth and Adolescence, 46(1), 165-179. https://doi.org/10.1007/s10964-016-0558-3.

Avila-Burgos, L., Valdez-Santiago, R., Híjar, M., Del Rio-Zolezzi, A., Rojas-Martínez, R., \& Medina-Solís, C. E. (2009). Factors associated with severity of intimate partner abuse in Mexico: Results of the first national survey of violence against women. Canadian Journal of Public Health, 100(6), 436-441. https://doi.org/10.1007/ bf03404340.

Ávila-Burgos, L., Valdez-Santiago, R., Barroso-Quiab, A., Híjar, M., Rojas, R., \& Del Río-Zolezzi, A. (2014). Prevalencia y factores asociados a violencia de Pareja en usuarias de servicios públicos de salud en México: Un análisis comparativo. Revista de Investigacion Clinica, 66(1), 45-58.

Blom, H., Högberg, U., Olofsson, N., \& Danielsson, I. (2014). Strong association between earlier abuse and revictimization in youth. $B M C$ Public Health, 14(1), 1-10. https://doi.org/10.1186/1471-2458-14715 .

Boladale, M., Yetunde, O., Adesanmi, A., Olutayo, A., \& Olanrewaju, I. (2015). Personality profiles and psychopathology among students exposed to dating violence at the Obafemi Awolowo University, IleIfe. Journal of Interpersonal Violence, 30(1), 168-190. https://doi. org $/ 10.1177 / 0886260514532718$.

Canedo, A. P., \& Morse, S. M. (2019). An estimation of the effect of women's employment on the prevalence of intimate partner violence in Mexico. Journal of Interpersonal Violence, 088626051987601. Advance online publication. https://doi.org/10. $1177 / 0886260519876016$

Carleton, R. N., Mulvogue, M. K., \& Duranceau, S. (2015). PTSD personality subtypes in women exposed to intimate-partner violence. Psychological Trauma: Theory, Research, Practice, and Policy, 7(2), 154-161. https://doi.org/10.1037/tra0000003.

Coșkuner Potur, D., Onat, G., \& Doğan Merih, Y. (2019). An evaluation of the relationship between violence exposure status and personality characteristics among infertile women. Health Care for Women International, 40(11), 1135-1148. https://doi.org/10.1080/ 07399332.2019 .1622704 .

Devynck, F., Kornacka, M., Sgard, F., \& Douilliez, C. (2016). Repetitive thinking in alcohol-dependent patients. Substance Use \& Misuse, 52, 1-11. https://doi.org/10.1080/10826084.2016.1222621.

Dowgwillo, E. A., Ménard, K. S., Krueger, R. F., \& Pincus, A. L. (2016). DSM-5 pathological personality traits and intimate partner violence among male and female college students. Violence and Victims, 31(3), 416-437. https://doi.org/10.1891/0886-6708.VV-D-1400109 .
Espinoza, G., Hokoda, A., Ulloa, E. C., Ulibarri, M. D., \& Castaneda, D. (2012). Gender differences in the relations among patriarchal beliefs, parenting and teen relationship violence in Mexican adolescents. Journal of Aggression Maltreatment \& Trauma, 21(7), 721-738. https://doi.org/10. 1080/10926771.2012.703289.

Esquivel-Santoveña, E. E., Rodríguez-Hernández, R., Gutiérrez-Vega, M., Castillo-Viveros, N., \& López-Orozco, F. (2019). Psychological aggression, attitudes about violence, violent socialization, and dominance in dating relationships. Journal of Interpersonal Violence, 0886260519842856, 088626051984285. https://doi.org/10.1177/0886260519842856.

Falb, K. L., Diaz-Olavarrieta, C., Campos, P. A., Valades, J., Cardenas, R., Carino, G., \& Gupta, J. (2014). Evaluating a health care provider delivered intervention to reduce intimate partner violence and mitigate associated health risks: Study protocol for a randomized controlled trial in Mexico City. BMC Public Health, 14(1). https://doi. org/10.1186/1471-2458-14-772.

Geneva Declaration Secretariat. (2015). Global Burden of Armed Violence 2015: Every Body Counts. Geneva Declaration Secretariat, 1-162. Retrieved from http://www.genevadeclaration. org/measurability/global-burden-of-armed-violence/global-burdenof-armed-violence-2015.html. Accessed Feb 2020.

González, A, J. \& Pazmiño, S, M. (2015). Cálculo e interpretación del Alfa de Cronbach Para el Caso de validación de la consistencia interna de un cuestionario, con dos posibles escalas tipo Likert. Revista Publicando. Retrieved from https://revistapublicando.org/ revista/index.php/crv/article/view/22/pdf 11 accessed 28 September 2020

Gupta, J., Willie, T. C., Harris, C., Campos, P. A., Falb, K. L., Moreno, C. G., Olavarrieta, D. C., \& Okechukwu, C. A. (2018). Intimate partner violence against low-income women in Mexico City and associations with work-related disruptions: A latent class analysis using crosssectional data. Journal of Epidemiology and Community Health, 72(7), 605-610. https://doi.org/10.1136/jech-2017-209681.

Hernández-Avila, M., Garrido, F., \& Salazar-Martínez, E. (2000). Sesgos en estudos epidemiológicos. Salud Pública de Mexico, 42(5), 438446.

Hines, D. A., \& Saudino, K. J. (2008). Personality and intimate partner aggression in dating relationships: The role of the "big five.". Aggressive Behavior, 34(6), 593-604. https://doi.org/10.1002/ab. 20277.

Jafrani, S., Zehra, N., Zehra, M., Ali, S. M. A., Mohsin, S. A. A., \& Azhar, R. (2017). Assessment of personality type and medical specialty choice among medical students from Karachi; using myersBriggs type indicator (MBTI) tool. Journal of the Pakistan Medical Association, 67(4), 520-526.

Levin, K. A. (2006). Study design III: Cross-sectional studies. EvidenceBased Dentistry, 7(1), 24-25. https://doi.org/10.1038/sj.ebd. 6400375 .

Martinou, E., Allan, H., \& Vig, S. (2015). Personality differences among junior postgraduate trainees in the United Kingdom. Journal of Surgical Education, 72(1), 122-127. https://doi.org/10.1016/j. jsurg.2014.06.014.

McNaughton Reyes, H. L., Foshee, V. A., Bauer, D. J., \& Ennett, S. T. (2014). Proximal and time-varying effects of cigarette, alcohol, marijuana and other hard drug use on adolescent dating aggression. Journal of Adolescence, 37(3), 281-289. https://doi.org/10.1016/j. adolescence.2014.02.002.1.

Mcneish, D. (2018). Thanks coefficient alpha, we' 11 take it from here. Psychological Methods, 23(3), 412-433. https://doi.org/10.1037/ met0000144.

Miller, A. B., Williams, C., Day, C., \& Esposito-Smythers, C. (2017). Effects of cognitive distortions on the link between dating violence exposure and substance problems in clinically hospitalized youth. Journal of Clinical Psychology, 73(6), 733-744. 
Olaiz, G., Uribe, P. \& Del-Rio, A. (2009). Encuesta Nacional sobre Violencia contra las Mujeres 2006 ENVIM. 1-140. Retrieved from http://cedoc.inmujeres.gob.mx/documentos_download/ENVIM 2006.pdf. Accessed Nov 2019.

Organization of Economic Cooperation and Development. (2019). Under Pressure: The Squeezed Middle Class, the middle-class online calculator. Organization of Economic Cooperation and Development. Retrieved from https://www.oecd.org/social/under-pressure-thesqueezed-middle-class-689afed1-en.htm. Accessed Sep 2020.

Papalia, D. E., Feldman, R. D., \& Martorell, G. (2015). Experience human development (13th ed.). New York: McGraw-Hill.

Petrides, J., Collins, P., Kowalski, A., Sepede, J., \& Vermeulen, M. (2019). Lifestyle changes for disease prevention. Primary Care Clinics in Office Practice, 46(1), 1-12. https://doi.org/10.1016/j. pop.2018.10.003.

Porcerelli, J. H., Hurrell, K., Cogan, R., Jeffries, K., \& Markova, T. (2015). Personality assessment screener, childhood abuse, and adult partner violence in african american women using primary care. Assessment, 22(6), 749-752. https://doi.org/10.1177/1073191115606213.

Rivera-Rivera, L., Allen-Leigh, B., Rodríguez-Ortega, G., ChávezAyala, R., \& Lazcano-Ponce, E. (2007). Prevalence and correlates of adolescent dating violence: Baseline study of a cohort of 7960 male and female Mexican public school students. Preventive Medicine, 44(6), 477-484. https://doi.org/10.1016/j.ypmed.2007. 02.020 .

Romero Mendoza, M. P., Gómez-Dantes, H., Manríquez Montiel, Q., Saldívar Hernández, G. J., Campuzano Rincón, J. C., Lozano, R., \& Medina-Mora Icaza, M. E. (2018). The invisible burden of violence against girls and young women in Mexico: 1990 to 2015. Journal of Interpersonal Violence, 0886260517753851, 088626051775385. https://doi.org/10.1177/0886260517753851.

Rothman, E. F., Stuart, G. L., Greenbaum, P. E., Heeren, T., Bowen, D. J., Vinci, R., Baughman, A. L., \& Bernstein, J. (2011). Drinking style and dating violence in a sample of urban, alcohol-using youth. Journal of Studies on Alcohol and Drugs, 72(4), 555-566. https:// doi.org/10.15288/jsad.2011.72.555.

Schultz, D. P., \& Shultz, S. E. (2009). Teorías de la Personalidad. Cengage Learning, 9, 1-542.
Sedgwick, P. (2015). Bias in observational study designs: Cross sectional studies. British Medical Journal (Clinical Research Ed.), 350, 2-3. https://doi.org/10.1136/bmj.h1286.

Shirzad, G. (2016). The role of the Myers-Briggs personality type and emotional intelligence in marital satisfaction among married female students at Tehran University. Global Journal of Health Science, 8(10), 50. https://doi.org/10.5539/gjhs.v8n10p50.

Temple, J. R., Shorey, R. C., Fite, P., Stuart, G. L., \& Le, V. D. (2013). Substance use as a longitudinal predictor of the perpetration of teen dating violence. Journal of Youth and Adolescence, 42(4), 596-606. https://doi.org/10.1007/s10964-012-9877-1.

The Myers and Briggs Foundation. (2020). Retrieved from http://www. myersbriggs.org. Accessed 10 April 2020.

Ulibarri, M. D., Salazar, M., Syvertsen, J. L., Bazzi, A. R., Rangel, M. G., Orozco, H. S., \& Strathdee, S. A. (2019). Intimate partner violence among female sex workers and their noncommercial male partners in Mexico: A mixed-methods study. Violence Against Women, 25(5), 549-571. https://doi.org/10.1177/1077801218794302.

Ulloa, E. C., Hammett, J. F., O’Neal, D. N., Lydston, E. E., \& Aramburo, L. F. L. (2016). The big five personality traits and intimate partner violence: Findings from a large, nationally representative sample. Violence and Victims, 31(6), 1100-1115. https://doi.org/10.1891/ 0886-6708.VV-D-15-00055.

Valdez-Santiago, R., Híjar-Medina, M. C., Salgado De Snyder, V. N., Rivera-Rivera, L., Avila-Burgos, L., \& Rojas, R. (2006). Escala de violencia e índice de severidad: Una propuesta metodológica Para medir la violencia de Pareja en mujeres mexicanas. Salud Publica de Mexico, 48(SUPPL. 2), 221-231. https://doi.org/10.1590/s003636342006000800002 .

WHO. (2017). Violence against women. World Health Organization, 70, 94-102 Retrieved from https://www.who.int/news-room/factsheets/detail/violence-against-women. Accessed Nov 2019.

Yang, C., Richard, G., \& Durkin, M. (2016). The association between Myers-Briggs type Indicator and psychiatry as the specialty choice. International Journal of Medical Education, 7, 48-51. https://doi. org/10.5116/ijme.5698.e2cd.

Publisher's Note Springer Nature remains neutral with regard to jurisdictional claims in published maps and institutional affiliations. 